\title{
Análise Idiossincrática dos Discursos proferidos nas decisões judiciais sobre Erro Médico no TJDFT: um estudo qualitativo ${ }^{1}$
}

Idiosyncratic analysis of the Discourses pronounced in the judicial decisions on Medical Error in the TJDFT: a qualitative study

Análisis idiosincrático de los discursos pronunciados en las decisiones judiciales sobre error médico en el TJDFT: un estudio cualitativo

Talita Rodrigues Gomes²

RESUMO: Objetivo - Conhecer os argumentos utilizados nas decisões judiciais procedentes sobre erro médico que foram julgadas no TJDFT. Metodologia - Optou-se por uma metodologia qualitativa com análise idiossincrática do discurso com a finalidade de conhecer pressupostos classificados como: legal, processual e material. Resultados - Há uso diferenciado da legislação para o julgamento de casos de erro médico de forma distinta para o setor público e o setor privado assim como há julgados em vista de problemas processuais e erros formais no processo civil. Conclusão - É possível aferir a partir do discurso analisado tanto a negligência, como imperícia e imprudência no trato dos pacientes o que evidencia falhas no sistema de saúde. Constata-se a necessidade de efetivação de ações de saúde e propostas de formação dos profissionais de saúde e do direito mais humanizadas.

Palavras-chave: Erro Médico, Judicialização, Análise Qualitativa, Saúde Pública

\begin{abstract}
Objective - It is necessary to knowledge the importance and the factors associated to medical errors to promote measures in order to avoid professional malpractice. In order to understand the arguments used in sentences regarding medical error that were pronounced in the TJDFT. Methods - this research made a qualitative analysis through an idiosyncratic reading of the sentences conducted with the purpose of understanding assumptions classified as: legal, procedural and material. Results - We observed differentiated uses of legislation for the lawsuits regarding medical error in a different way for the public sector and the private sector; we also observed the outcome of the complaints due to procedure and formal errors in civil proceedings. Conclusion It is possible to estimate from the complaints problems such as negligence, malpractice and presumption in the treatment of the patients, which demonstrates failures in the health system. There is a need for health actions and proposals of health professionals and law practitioners training with a more humanized manner.
\end{abstract}

Keywords: Medical Error, Judicialization, Qualitative Analysis, Public Health

\footnotetext{
${ }^{1}$ Este trabalho é fruto das pesquisas sobre O Erro Médico nos Tribunais do Distrito Federal, financiado pela Fundação de Amparo a Pesquisa do Distrito Federal - FAP-DF ( EFP_00013333)

${ }_{2}^{2}$ Mestre em Saúde Coletiva pela Universidade de Brasília. Email - talitaum@gmail.com
} 
RESUMEN: Objetivo - Conocer los argumentos utilizados en las decisiones judiciales procedentes sobre error médico que fueron juzgadas en el TJDFT. Metodología - Se optó por una metodología cualitativa con análisis idiosincrático del discurso con la finalidad de conocer presupuestos clasificados como: legal, procesal y material. Resultados - Hay uso diferenciado de la legislación para el juicio de casos de error médico de forma distinta para el sector público y el sector privado, así como hay juzgados en vista de problemas procesales y errores formales en el proceso civil. Conclusión - Es posible aferir a partir del discurso analizado tanto la negligencia, como impericia e imprudencia en el trato de los pacientes lo que evidencia fallas en el sistema de salud. Se constata la necesidad de efectividad de acciones de salud y propuestas de formación de los profesionales de salud y del derecho más humanizadas.

Palabras Ilave: Error Médico, Judicialización, Análisis Cualitativo, Salud Pública

\section{Introdução}

Os erros médicos, quase sempre, causam danos e sofrimento aos pacientes, o que, aliado a uma relação médico-paciente insatisfatória, é responsável por grande parte das denúncias feitas nos Conselhos Regionais de Medicina (CRM) (1). Segundo Chehuen Neto et. al. (2), erro médico é o dano provocado no paciente pela ação ou omissão do médico, no exercício da profissão, e sem a intenção de cometê-lo. Há três possibilidades de suscitar o dano e alcançar o erro: imprudência, imperícia e negligência. A negligência, consiste em não fazer o que deveria ser feito; a imprudência consiste em fazer o que não deveria ser feito e a imperícia em fazer mal o que deveria ser bem feito.

Os Conselhos Regionais de Medicina são autarquias federais consideradas especiais e cuja finalidade é proteger a sociedade dos maus médicos (3). Deslizes cometidos por profissionais de outras áreas podem não acarretar maiores consequências, mas os erros dos médicos frequentemente provocam resultados indesejados e, muitas vezes, sequelas irreversíveis (4). Reconhecer a importância e conhecer os fatores relacionados aos erros médicos é fundamental para formular medidas no sentido de evitar a má prática profissional (5).

Vem ocorrendo no Brasil e no mundo aumento nas demandas judiciais na área cível e na esfera administrativa por parte de advogados que buscam indenizações e na atuação dos conselhos de medicina na abertura de processos éticos profissionais (6).

A prevenção de erros deve basear-se na busca de causas reais, que geralmente incluem erros no sistema de organização e implementação do serviço. Erros devem ser 
aceitos como evidência de falha no sistema, e encarados como oportunidade de revisão do processo e aprimoramento da assistência prestada ao paciente (7).

A segurança do paciente, uma importante dimensão da qualidade em saúde, se tornou foco de atenção a partir do relatório apresentado pelo Instituto de Medicina - To err is human -, que apontou a alta frequência de eventos adversos resultantes do cuidado hospitalar, ou seja, incidentes que resultavam em dano para o paciente, e que mais da metade dos casos eram ocasionados por erros médicos (8).

Ao tratar o erro médico como uma conduta antiética os processos tramitam junto sob sigilo junto aos Conselhos de Medicina, o que acaba fazendo a sociedade desconhecer a gravidade problema. Ao revés, nos tribunais, os erros médicos costumam ser traduzidos em processos judiciais de caráter público que tramitam em Varas Civis e Varas Criminais e acabam sendo de conhecimento público e de livre acesso.

Segundo Bonetti et. al. (9) a negligência médica envolve danos, lesões ou morte podendo ser atribuído ao comportamento negligente por um médico ou de outros profissionais de saúde. Muitas vezes pacientes e familiares que acreditam ter sido vítimas de negligência médica recorrem contra os prestadores de cuidados de saúde. Isto tem um forte impacto em termos de custos e os reembolsos, e leva médicos, profissionais de saúde e organizações de saúde a aderirem políticas de seguro de responsabilidade civil para compensar seus riscos.

Ao contrário do apontado por Makary; Daniel (10), erros médicos são apontados como a terceira maior causa de morte nos Estados Unidos num estudo que analisa os dados de mortalidade no país por oito anos, onde constataram que mais de 250 mil mortes por ano são atribuídas a erros assim como na Itália, o número anual de processos que alegam negligência médica tem aumentado ao longo dos últimos anos para todas as tipologias de reivindicações como: lesão corporal, lesões no momento do nascimento, morte e outros danos materiais (9).

Segundo Cordero et. al. (6), em 7 anos, o número de médicos denunciados no Conselho Regional de Medicina do Estado de São Paulo (10) aumentou em 75\%. De 2.023 médicos denunciados em 2000, o número subiu para 3.569 em 2006, o que 
demonstra que no Brasil os processos contra médicos também atingem níveis expressivos.

Para Rodríguez; Riva e Serratosa (12) a responsabilidade médica é um fenômeno inseparável dos cuidados de saúde, sendo assim uma lesão, uma incapacitação, ou mesmo o óbito do paciente proveniente de tratamento médico pode ser considerada um crime (13)(14).

Os processos judiciais têm interesse público e estão disponíveis para consulta, seja na internet, em forma sintética, seja nos cartórios dos Fóruns, para vistas dos solicitantes. Este caráter público do processo judicial faz com que seja possível o acesso aos dados referentes a toda a sorte de assunto, incluído os erros médicos. Com o objetivo de conhecer os argumentos utilizados nas decisões judiciais procedentes sobre erro médico que foram julgadas no TJDFT, entre os anos de 2013 e 2015 é que foi realizado pesquisa, cujos resultados são discutidos neste artigo.

\section{Metodologia}

Foi realizada uma pesquisa jurisprudencial, com o erro médico como objeto material. Tratou-se de uma pesquisa exploratória, analítico-descritiva de base qualitativa, cuja unidade de consulta foi o processo judicial contendo Apelações Cíveis e/ou Apelações Criminais julgadas em segunda instância no TJDFT.

Foi consultada a base jurisprudencial do referido tribunal, utilizando-se para a seleção das ações o descritor "erro médico".

Os princípios que nortearam a pesquisa qualitativa se situam nas correntes cujos resultados provêm de uma visão extraída a partir do discurso do próprio sujeito pesquisado, ou seja, o julgador dos casos sobre erro médico colocados sob seu julgamento.

Para as análises dos argumentos utilizados pelos julgadores em suas decisões, optou-se em utilizar o Método da Análise do Discurso por sua técnica de Análise Idiossincrática (15), que representa o ato de extrair da fala do sujeito, unidades significativas que explicitam a consciência que este momento tem do fenômeno. $O$ discurso, nesta proposta, está delimitado ao descrito como argumentos provenientes da transcrição dos acórdãos analisados. 
Optou-se em selecionar apenas as decisões procedentes, a fim de conhecer-lhes o discurso a partir de 3 pressupostos: legal, processual e material.

Por pressuposto legal entende-se todo o arco normativo elencado pelo julgador em sua decisão, isso possibilita conhecer as regras jurídicas utilizadas para as decisões. Por pressuposto processual entende-se os entendimentos jurídicos que possam ter alterado a normal tramitação do processo, tais como indeferimento de provas, pedido de perícia etc. Por fim, o pressuposto material, entendido neste trabalho como aquele que diz respeito diretamente ao mérito da causa, os argumentos fáticos trazidos aos autos que embasaram a decisão.

Minayo (16) defende que a análise do discurso pode ser realizada por um conjunto de abordagens interdisciplinares, e tem seu marco inicial com Michael Pêcheux na década de 1960, onde seu objetivo é realizar uma reflexão da apreensão dos significados. Assim é que se compreende que a materialidade específica da ideologia é o discurso. E a materialidade do discurso é a língua que constituiu a relação línguadiscurso-ideologia. Complementando a isso Pêcheaux (17) afirma que não há discurso sem sujeito, como não há sujeito sem ideologia: o indivíduo é interpelado como sujeito pela ideologia e é assim que a língua faz sentido.

O conceito de discurso é elaborado exatamente como meio de contemplar a articulação entre o objeto língua e os processos ideológicos de constituição de sentido pela reconstrução dos processos discursivos

\section{Resultados e Discussão}

Dentre os 427 processos encontrados no sítio do TJDFT foram selecionados para a pesquisa 204 demandas relacionadas ao erro médico e distribuídas no intervalo temporal definido para a pesquisa. Dentre esses, foram separados os acórdãos com provimento do pedido, isto é, as ações julgadas procedentes ao autor ou ao réu, na ação.

Foram desconsideradas as ações julgadas improcedentes porque o primeiro grupo de algum modo já sinaliza o discurso adotado pelos julgadores para dar provimento a um pedido, a contrário senso dos julgados improcedentes. 
As vítimas por erro médico podem recorrer ao Poder Judiciário com ações em âmbito penal, cível e ainda pela via da ação disciplinar junto ao conselho profissional em busca de medidas disciplinares contra o prestador de cuidados de saúde. Pode ainda haver a conciliação em que as partes, vítima e médico, venham a acordar a eventual reparação dos danos havidos, sendo que a conciliação implica na renúncia ao direito de queixa ou representação junto ao Judiciário (art. 74, § único, da Lei 9.099/95).

Os processos analisados no TJDFT, em segunda instância, consubstanciados em demandas sobre erro médico foram julgados pelas Turmas Cíveis $\left(1^{\underline{a}}, 2^{\underline{a}}, 3^{\underline{a}}, 4^{\underline{a}}, 5^{\underline{a}}\right.$ e $6^{\underline{a}}$ Turma Cível) como também pelos Juizados Especiais Cível e/ou Criminal (1 ${ }^{\underline{a}}$ e $2^{\underline{a}}$ Câmara Cível e pela $2^{\text {a }}$ Turma Criminal). Tal difusão no julgamento das ações movidas pelos pacientes acabam por ter grande representatividade do tribunal, podendo-se afirmar que a análise das decisões proferidas pelas turmas e câmaras têm relevante representação de todo o tribunal estudado.

Figura 1 Tipos de requeridos nos processos entre 2013-2015 no TJDFT sobre erro médico.

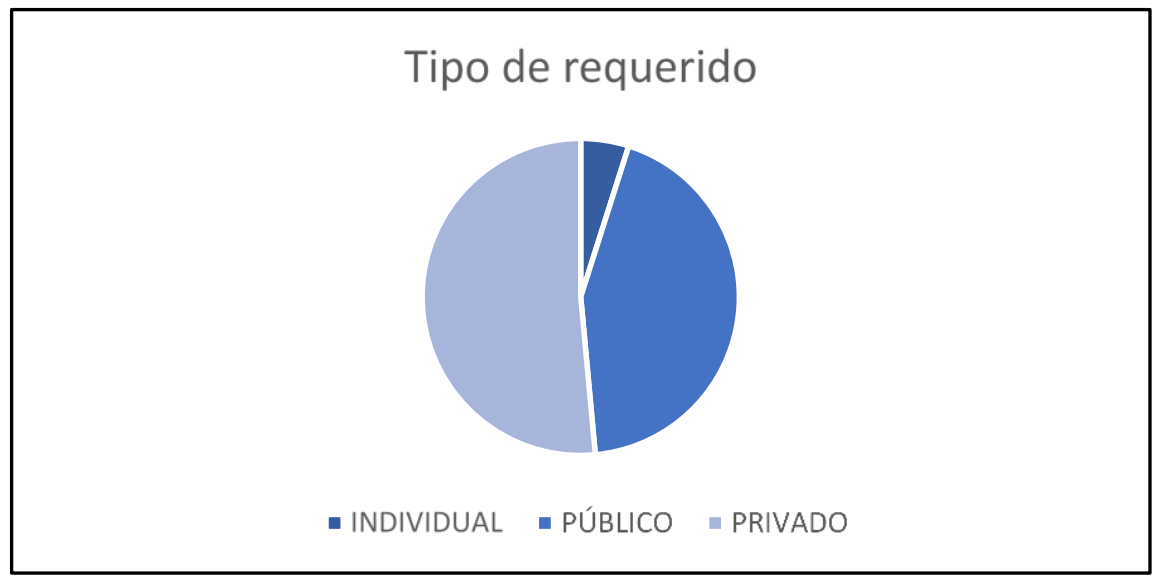

Fonte: TJDFT

Resta informar que a maioria das demandas por erro médico foram em desfavor do ente jurídico privado (51\%), ou sejam, hospitais e clínicas operantes no âmbito do Distrito Federal. O ente público, representado pelo SUS-DF, por seus hospitais da rede pública e conveniadas foram o segundo tipo mais comum encontrado na pesquisa 
(44\%). Com pouca expressão, foram localizados processos judiciais contra pessoas físicas representando os profissionais médicos (5\%).

Esta "pressão legal" nada mais é que o reflexo de uma sociedade em que a afirmação de direitos e a ideia de ter recebido uma lesão compensável é interpretada como a prática de saúde de um sistema público. Portanto, a responsabilidade criminal é definida como a responsabilidade pessoal de ser "bom profissional", enquanto a administração em saúde é cobrada a ser um "bom serviço de saúde" seja ela público ou privado (12).

Referente as sentenças analisadas observamos que $57 \%$ dos casos foram declarados improcedentes, 44\% declarados procedente, 19\% declarados parcialmente procedente e $2 \%$ dos processos relacionados ao erro médico foram extintos sem resolução do mérito. Para fins da análise do discurso, foram selecionadas apenas as decisões procedentes em um total de 44 decisões.

Os achados de Svider et. al. (18) analisou vereditos de processos referentes a eventos adversos em procedimento cirúrgico de carótida em que os desfechos dos casos foram resolvidos a favor do arguido em $67,5 \%$ dos casos e resultaram em pagamento de indenizações.

Dentre os argumentos encontrados nas sentenças dos processos coletados observa-se que nenhuma Apelação Cível se utilizou da terminologia relacionada a segurança do paciente e a Classificação Internacional de Segurança do Paciente (ICPS - sigla em inglês) da Organização Mundial de Saúde (OMS): "incidente sem danos", "evento adverso" e "segurança do paciente" em contrapartida observou-se que as definições jurídicas de crimes culposos ou dolosos segundo o Código Penal: negligência (4,9\%), imperícia (3,3\%) e imprudência (1,9\%) foram mais utilizadas.

A falta de unificação dos conceitos jurídicos e de segurança do paciente refletem certa deficiência por parte dos médicos relacionado ao conhecimento das leis implicadas na regulamentação de sua profissão, além da necessidade dos profissionais do Direito desenvolverem uma visão multidisciplinar ao conduzirem adequadamente um processo judicial, cercando-se de pessoas habilitadas para fazer julgamentos técnicos como perícias médicas (2). 
Quadro 1 - Análise dos Discursos inseridos nas Decisões Procedentes das Apelações Cíveis e Criminais com a Variável Normativa.

\begin{tabular}{|c|c|c|}
\hline $\begin{array}{l}\text { Discurso na linguagem do } \\
\text { acórdão }\end{array}$ & Unidade significativa & Asserções articuladas \\
\hline $\begin{array}{l}\text { 1) A saúde é direito de } \\
\text { todos e dever do } \\
\text { Estado, garantido } \\
\text { medianter políticas } \\
\text { sociais e econômicas } \\
\text { que visem à redução do } \\
\text { risco de doença e de } \\
\text { outros agravos }\end{array}$ & Citação ao art.196 CF/88 & $\begin{array}{l}\text { O cidadão tem direito a } \\
\text { saúde }\end{array}$ \\
\hline $\begin{array}{l}\text { 2) "[...] do ponto de vista } \\
\text { da execução de políticas } \\
\text { públicas para o fim de tornar } \\
\text { efetivos tais direitos } \\
\text { subjetivos constitucionais, } \\
\text { foram previstas as regras } \\
\text { dos arts. 196, } 197 \text { e } 198 \text { da } \\
\text { Constituição Federal, }\end{array}$ & Citação ao art. 196 CF/88 & $\begin{array}{l}\text { O cidadão tem direito à } \\
\text { saúde }\end{array}$ \\
\hline $\begin{array}{l}\text { 3) E o que dispõe o } \$ 4^{\circ} \\
\text { do artigo } 14 \text { do CDC, in } \\
\text { verbis: }\end{array}$ & $\begin{array}{l}\text { Citação ao Código de } \\
\text { Defesa do Consumidor }\end{array}$ & $\begin{array}{l}\text { O consumidor tem direito } \\
\text { a prestação de serviços }\end{array}$ \\
\hline $\begin{array}{l}\text { 4) "E o que se } \\
\text { extrai do disposto no } \\
\text { artigo } 186 \text { do Código } \\
\text { Civil: "Aquele que...." }\end{array}$ & $\begin{array}{l}\text { Citação ao Código Civil } \\
\text { Brasileiro }\end{array}$ & O cidadão tem direitos. \\
\hline 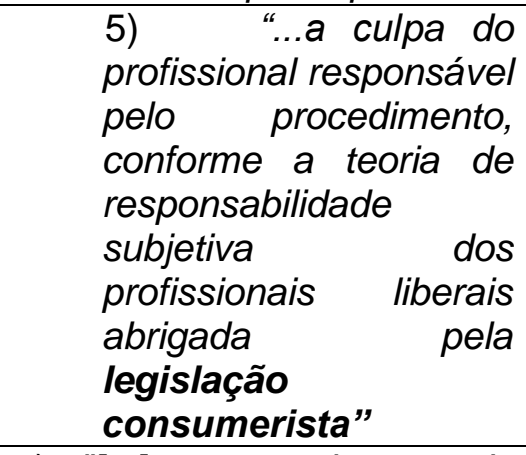 & $\begin{array}{l}\text { Citação ao Código de } \\
\text { Defesa do Consumidor }\end{array}$ & $\begin{array}{l}\text { O consumidor mantém } \\
\text { uma relação consumerista } \\
\text { com o prestado do serviço } \\
\text { de saúde }\end{array}$ \\
\hline $\begin{array}{l}\text { 6) "[...] com o intento de } \\
\text { regulamentação da matéria, } \\
\text { a Lei no } 8.080 \text {, de } 19 \text { de } \\
\text { setembro de 1990" }\end{array}$ & $\begin{array}{l}\text { Citação a } \text { Lei } \\
8080 / 90\end{array}$ & $\begin{array}{l}\text { O cidadão amparado pela } \\
\text { lei }\end{array}$ \\
\hline 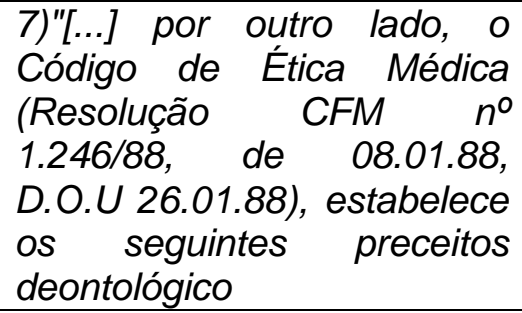 & $\begin{array}{l}\text { Citação ao } \text { Código de } \\
\text { Ética Médica }\end{array}$ & $\begin{array}{l}\text { O médico deve prestar } \\
\text { serviços de qualidade }\end{array}$ \\
\hline
\end{tabular}


$\mathrm{Na}$ totalidade das decisões procedentes analisadas, quando se deparou com menções à legislação, elas se restringiram à Constituição Federal, a Lei Federal 8080/90, o Código de Defesa do Consumidor, o Código Civil e o Código de Ética Médica.

O que chama a atenção é o uso diferenciado da legislação para o julgamento de casos de erro médico de forma distinta para o setor público e o setor privado. Quando se está julgando o erro médico no setor público, os julgadores se utilizam da Constituição Federal para reforçar o direito à saúde dos pacientes. No entanto, tal normativa não é trazida para a decisão quando se trata de julgar o erro médico no setor privado. Neste, os julgadores elencam o Código de Defesa do Consumidor.

Ora, segundo a Constituição Federal de 1988, o setor privado da saúde atua como complementar ao Sistema Único de Saúde-SUS, devendo, logicamente, que os princípios inerentes ao SUS serem igualmente aplicados no setor privado.

Quadro 2 - Análise dos Discursos inseridos nas Decisões Procedentes das Apelações Cíveis e Criminais com a Variável Processual.

\begin{tabular}{l|l|l}
\hline $\begin{array}{l}\text { Discurso na linguagem } \\
\text { do acórdão }\end{array}$ & Unidade significativa & Asserções articuladas \\
\hline 1) No momento & Violação do CPC & Prova pericial \\
processual $\begin{array}{r}\text { oportuno, } \\
\text { formulou pedido de }\end{array}$ & \\
produção de prova & \\
pericial, o qual foi & & \\
indeferido. & \\
\hline 2) Não logrando a & Nexo Causal não provado & Nexo Causal \\
consumidora demonstrar a & & \\
ocorrência de dano moral & \\
passível de reparação, & \\
tampouco o nexo de & \\
causalidade entre o & \\
suposto erro médico e o & \\
abalo moral que aquela & \\
alegou sofrer & \\
\hline
\end{tabular}

Alguns processos deixaram de ser julgados no mérito em vista de problemas processuais. Admira-se que tais obstáculos à obtenção de justiça e reparação sejam vislumbrados nos processos analisados. 
Erros de procedimento geralmente são provocados pelo advogado da parte e até mesmo pelo juiz, o que não é justificável, já que o paciente vítima de um erro médico acaba por ver-se vítima também de erro processual.

As abordagens sobre o erro processual são vastas na literatura jurídica. Os erros que podem ser sanáveis ou insanáveis habitam como certa frequência os processos no Judiciário. No processo civil o erro material é aquele que pode ser perceptível num primeiro olhar. Ex. erro quanto ao nome das partes na sentença, troca de letras. $O$ erro material pode ser corrigido pelo julgador.

O erro material dá-se quando o Juiz ou o Advogado escreve coisa diversa do que queria escrever, quando o teor da sentença ou despacho não coincide com o que o Juiz tinha em mente exarar. Fora dos casos de lapso manifesto por erro material o discurso jurídico fundamentador de facto e de direito da decisão contém o sentido do enquadramento jurídico dado pelo tribunal. (19)

O erro formal no processo civil pode ser relativizado. Segundo o princípio da instrumentalidade das formas os atos processuais reputam-se válidos quando realizados de outro modo, Ihe preencham a finalidade essencial art. 154 CPC.

Normalmente dizemos erro material aquele proveniente do direito civil, à matéria, direito substancial. Erro formal é aquele decorrente da forma, normalmente decorrente do procedimento, ou do direito processual, direito adjetivo.

Quadro 3 - Análise dos Discursos inseridos nas Decisões Procedentes das Apelações Cíveis e Criminais com a Variável Material (Fática).

\begin{tabular}{|c|c|c|}
\hline $\begin{array}{l}\text { Discurso na linguagem } \\
\text { do acórdão }\end{array}$ & Unidade significativa & Asserções articuladas \\
\hline $\begin{array}{l}\text { 1) Constitui ato ilícito } \\
\text { indenizável pelo Estado, } \\
\text { por ato praticado em } \\
\text { hospital público, } \\
\text { consistente na demora } \\
\text { para realizar parto de } \\
\text { paciente com a bolsa rota, } \\
\text { além de não ministrar } \\
\text { antibióticos necessários } \\
\text { para evitar a } \\
\text { contaminacão fetal a }\end{array}$ & Demora no atendimento & Negligência \\
\hline $\begin{array}{l}\text { 2) "não Ihe prestou } \\
\text { assistência pós-operatória } \\
\text { adequada, a despeito de }\end{array}$ & Não prestou assistência & Negligência \\
\hline
\end{tabular}




\begin{tabular}{|c|c|c|}
\hline $\begin{array}{l}\text { ter sido insistentemente } \\
\text { contatado pelos seus } \\
\text { familiares, já que ela } \\
\text { apresentava quadro de } \\
\text { fortes dores." }\end{array}$ & & \\
\hline $\begin{array}{l}\text { 3)"Sustenta que, mesmo } \\
\text { depois dessa segunda } \\
\text { cirurgia de revisão e } \\
\text { diante do persistente } \\
\text { quadro de dor o réu } \\
\text { continuou a Ihe negar } \\
\text { qualquer assistência pós- } \\
\text { operatória" }\end{array}$ & Não prestou assistência & Negligência \\
\hline $\begin{array}{l}\text { 4)" A leitura apurada do } \\
\text { diário de saúde, permite } \\
\text { concluir, mesmo sem } \\
\text { auxílio de perícia judicial, } \\
\text { que durante aqueles dias } \\
\text { de internação, a equipe } \\
\text { médica constatou que o } \\
\text { quadro de saúde da } \\
\text { autora era grave e } \\
\text { decorria da infecção } \\
\text { desde o primeiro } \\
\text { procedimento cirúrgico. }\end{array}$ & Agravamento do quadro & Imprudência \\
\hline $\begin{array}{l}\text { 5)"[...] assevera que, } \\
\text { ainda na rede pública, não } \\
\text { conseguiu ser submetida } \\
\text { à cirurgia recomendada, } \\
\text { ante a dificuldade de } \\
\text { aquisição de material e } \\
\text { anestesia [...]" }\end{array}$ & $\begin{array}{l}\text { Falta de material para } \\
\text { cirurgia }\end{array}$ & Negligência \\
\hline $\begin{array}{l}\text { 6) A Autora deu à luz a } \\
\text { uma criança que veio a } \\
\text { óbito. Alegam também } \\
\text { que o } \quad \text { médico } \\
\text { acompanhou o parto de } \\
\text { outras quatro parturientes } \\
\text { ao mesmo tempo }\end{array}$ & Excesso de trabalho & Imprudência \\
\hline $\begin{array}{l}\text { 7) Menor de } 4 \text { anos } \\
\text { descreve o sofrimento } \\
\text { durante quase um mês de } \\
\text { internação, necessidade } \\
\text { de uma segunda cirurgia } \\
\text { para limpeza de órgãos, } \\
\text { sequela estética, } \\
\text { vergonha do corpo e } \\
\text { pânico. }\end{array}$ & Muito tempo de internação & Imperícia \\
\hline
\end{tabular}

Fonte: Fragmentos das decisões dos processos do TJDFT 
Da análise do discurso contidos nas decisões judiciais em $2^{\circ}$ grau de jurisdição, vê-se que é possível aferir tanto a negligência, como imperícia e imprudência no trato dos pacientes o que evidencia falhas no sistema de saúde.

Ferraz (20) afirma que o tratamento médico não é ausente de risco e que esses podem ser classificados em leves, moderados ou graves, razão de se tomar um Termo de Responsabilidade do paciente previamente a qualquer procedimento em que envolvem riscos.

Chehuen Neto et. al. (2) discute a percepção de alunos de Medicina e Direito a respeito de erro médico e afirma que essas modalidades se entrelaçam pela relevância na vida profissional do médico como agente ativo, e a vida do profissional que estuda as implicações legais da prática médica. Devido aos apelos por condutas éticas esta discussão ganha importância na graduação devido a necessidade de se formarem profissionais mais bem informados e preparados para as necessidades que emergem na sociedade.

Implica igualmente em erros com consequentes responsabilidades a frágil formação do médico posto que, segundo dados (21) o Brasil possui 180 escolas de medicina, o que acaba por transformar o ensino em produto comercializável contribuindo para a proliferação de faculdades e para a queda na qualidade do ensino. Há casos em que são autorizados novos cursos sem o pré-requisito do hospital-escola (22).

Dados avaliativos do CREMESP, o desempenho dos estudantes do sexto ano do curso de Medicina das escolas do Estado de São Paulo obteve um índice de reprovação de $61 \%$ (11). A educação médica, neste contexto, tem dois papéis, o de informador e o de formador. Enquanto o primeiro tem a função de fornecer ao estudante conhecimentos científicos e de natureza técnica essenciais ao exercício da futura profissão, o segundo é responsável pelo amadurecimento de uma personalidade adulta e equilibrada, capaz de entender a complexa estrutura biopsicossocial do paciente (1).

A imperícia também pode ser avaliada em relação ao progresso científico à época e ao profissional. O médico desatualizado poderá ser reputado imperito quando o desuso de determinada prática.

Estudos mostram que a maioria dos médicos que respondem por erro está graduada há mais de 10 anos (07) (23). O tempo de profissão acima de 10 anos traz ao 
médico falsa segurança de experiência, tendência ao afastamento dos livros e necessidade de maior aporte financeiro para o crescimento patrimonial, favorecendo sua exposição aos riscos (24).

\section{Conclusão}

O cuidado em saúde é objeto de investigação científica por vários profissionais de saúde. Erros médicos na prática em saúde ocorre mais frequentemente por causas organizacionais e técnicas como a má formação profissional. É importante notar que os atos jurídicos relacionados a saúde exigem que os profissionais de saúde em seu trabalho forneçam um certo padrão de conhecimento, competência e cuidados na prestação do cuidado médico.

Ao analisar as sentenças proferidas pelo TJDFT constata-se a necessidade de efetivação de ações de saúde mais humanizadas, e propostas de formação do profissional da saúde, que contemple aspectos inerentes as relações entre o profissional e seus pares, as relações entre os pacientes e os familiares, e a humanização dos serviços de saúde. Uma boa relação médico-paciente é a melhor maneira de prevenir denúncias e processos contra o médico.

Aos magistrados, também se faz necessário a capacitação de forma a auxiliar no julgamento dos pleitos, contribuindo para o enfrentamento racional da questão do erro médico, fomentado em conceitos técnicos e não apenas de base jurídica. Encorajando juristas mais comprometidos com a prática médica e menos sujeitos a elementos processuais.

\section{Referências}

1. Bitencourt AGV, Neves NMBC, Neves FBCS, Brasil ISPS, Santos LSC. Análise do erro médico em processos ético-profissionais: implicações na educação médica. Revista Brasileira de Educação Médica 2007;31(3).

2. Chehuen Neto JA, Sirimarco MT, Figueiredo NSV, Barbosa TN, Silveira TG. Erro médico: a perspectiva de estudantes de medicina e direito. Revista Brasileira de Educação Médica, v. 35, n. 1, p. 5-12, 2011.

3. Fujita RR, Santos IC. Denúncias por erro médico em Goiás. Revista da Associação Médica Brasileira v. 55, n. 3, p. 283-289, 1992. 
4. Volpe CRG, Pinho DLM, Stival MM, Karnikowski MGO. Medication errors in a public hospital in Brazil. British Journal Of Nursing, v. 23, n. 11, p. 552, 2014.

5. Ribeiro WC, Julio RS. Reflexões sobre erro e educação médica em Minas Gerais. Revista Brasileira de Educação Médica, v. 35, n. 2, p. 263-267, jun. 2011.

6. Silva J.A.C., Brito M.V.H., Brito N.B., Gonçalves R.S., Fonseca S.N.S., Oliveira A.J.B.. Natureza e Especialidades envolvidas nas Denúncias sobre Erros Médicos que Originaram Processos Ético-Profissionais no Conselho Regional de Medicina do Estado do Pará. Ciências Biológicas e da Saúde, v. 12, n. 2, p. 27-30, 2010.

7. Carvalho M, Vieira AA. Erro médico em pacientes hospitalizados. Jornal de Pediatria, v. 78, p. 261-268, 2002.

8. Kohn LT, Corrigan JM, Donaldson MS To Err Is Human. Building a Safer Health System, Volume 6. Washington, D.C.: Institute of Medicine. National Academies Press, 1999. v. 2

9. Bonetti M, Cirillo P, Musile Tanzi P, Trinchero E. An Analysis of the Number of Medical Malpractice Claims and Their Amounts. Public Library of Science, PloS ONE, v. 11, n. 4, 2016.

10. Makary, M.A.; Daniel, M. Medical Error - the third leading cause of death in the US. British Medical Journal, v. 353, p. i2139, 2016.

11. Conselho De Medicina do Estado de São Paulo (CREMESP). Especialidades Médicas. Disponível em: http://www.cremesp.org.br. [Acesso em 30.1.2017].

12. Rodríguez Hornillo M., Riva Moreno C. De la, Serratosa Sánchez-lbargüen A.. Responsabilidad sanitaria: responsabilidad personal del médico vs. responsabilidad del sistema sanitario. Cuadernos de Medicina Forense, v. 17, n. 2, p. 59-66, 2011.

13. Henrique, J.; Martins, S. A Responsabilidade Penal por Erro Médico. Revista Jurídica da FURB, v. 3, p. 51-64, 1998.

14. Udelsmann A. Responsabilidade civil, penal e ética dos médicos. Rev Assoc Med Bras. 2002;48(2):172-82.

15. Maeda, A. M. C.; Pollak, D. F.; Martins, M. A. V.. A compreensão do residente médico em reumatologia no atendimento aos pacientes com fibromialgia. Revista Brasileira de Educação Médica, v. 33, n. 3, p. 393-404, set. 2009.

16. Minayo MCS, organizadora. Pesquisa social: teoria, método e criatividade., 20 ed. Petrópolis (RJ) Vozes, 2010.

17. Pêcheux, Michel; Fuchs, Catherine. A propósito da análise automática do discurso: atualização e perspectivas Campinas, SP: Ed. da Unicamp: 163-252. 1997.

18. Peter F. Svider, MD, Gian-Paul Vidal, MD, Osvaldo Zumba, MD, Andrew C. Mauro, BA, Paul B. Haser, MD, Alan Graham, MD, Saum Rahimi, MD. Adverse events in carotid endarterectomy from a medicolegal perspective. Vascular and Endovascular Surgery, v. 48, n. 5-6, p. 425-429, 2014.

19. Pereira, J. T. R. "Erro material" - em que consiste? Disponível em: <https://www.verbojuridico.net/doutrina/artigos/oadvogado_57.html>. Acesso em: 1 fev. 2017.

20. Ferraz, E. M. Complicação ou erro médico? Revista do Colégio Brasileiro de Cirurgiões, v. 33, n. 4, p. 205-206, ago. 2006. 
21. Conselho Federal de Medicina (CFM) divulga dados sobre concentração de médicos no Brasil. CREMESC. Disponível em: http://www.cremesc.org.br. [Acesso em 30.1.2017]

22. Moraes, I.N.. Erro médico e a Lei. São Paulo: LEJUS, 1998.

23. Gomes JCM, França GV. Iniciação à Bioética. Parte IV - Bioética Clínica. Erro Médico. Rio de Janeiro: Guanabara Koogan, 2002.

24. Koeche L.G., Censi I., Bortoluzzi M.C., Bonamigo E.L.. Prevalência do erro médico entre as especialidades médicas nos processos julgados pelo Conselho Regional de Medicina do Estado de Santa Catarina. Arquivos Catarinenses de Medicina, v. 42 , n. 4 , p. $45-53,2013$.

Recebido em: 19.11.2017

Aprovado em: 20.12.2017

\section{Como citar este artigo:}

Gomes TR. Análise Idiossincrática dos Discursos proferidos nas decisões judiciais sobre Erro Médico no TJDFT: um estudo qualitativo. Revista Cadernos Ibero-Americanos de Direito Sanitário. 2017 out./dez, 6(4):55-69. 